\title{
Compaixão e Indignação: duas paixões retratadas na canção "Ana Rosa”
}

\author{
Elizabeth Rizzi Lyra \\ Fabíola Mirella Dias Roque da Silva
}

\section{Introdução}

T início do século passado, o Brasil era um país predominantemente rural, e como consequência disso, por volta de 1910 já existiam algumas duplas sertanejas muito embora não tivessem ganhado destaque no meio musical. Alguns anos mais tarde surgiram duas grandes gravadoras: Columbia e RCA Victor. Elas, porém, recusavam-se em gravar as chamadas "músicas de tema rural" e um dos motivos era não saber se este estilo musical conquistaria algum público. Foi então que o jornalista, ator, humorista e poeta de Tietê -SP, Cornélio Pires, fez uma aposta e produziu o primeiro disco de música caipira. Foi ele quem valorizou e difundiu a música caipira ao criar o grupo de artistas caipiras chamados de Turma Cornélio Pires. Para isso, arrumou dinheiro e bancou, sem o auxílio de gravadoras, a produção de 5 discos de 78 rotações.

A primeira música gravada foi "Jorginho do sertão", de autoria do próprio Cornélio Pires, com a dupla Caçula e Mariano. É o primeiro disco de música caipira, gravado no Brasil, que se tem registro. O sucesso foi imediato uma vez que esse gênero musical era desconhecido tanto pelas pessoas das grandes cidades, quanto pelas pessoas da roça que, ao ouvir as narrativas que embalavam as canções, inclusive nas modas de viola, encantaram-se e identificaram-se com o que era relatado, pois tratava-se de materializar em canção o cotidiano do trabalhador campesino, tanto que muitas gravadoras passaram a investir nesse gênero musical, o que deu oportunidade para muitos artistas mostrarem seu trabalho para o grande público da cidade grande. Cornélio, o "contador de causos do sertão", passou a se apresentar com seus artistas para um público cada vez maior e mais diversificado. 
Antes de Cornélio, a música caipira era pouco conhecida fora de seu meio. Foi o grande poeta e compositor que deu o primeiro passo para a popularização do gênero. Na época era muito comum associar a imagem do caipira a um homem ignorante e incapaz de criar composições elaboradas, o que explica, em parte, a resistência das gravadoras em investir nesse gênero musical. No início, os artistas tinham como principal fonte de renda trabalhos paralelos, muitas vezes associado à lavoura ou outros serviços do campo. Demorou até que esses primeiros compositores e cantores pudessem viver de seu trabalho musical. Foi somente a partir da década de 1940, que as portas realmente se abriram para os cantadores caipiras. Isso possibilitou visibilidade do seu trabalho, não só no meio rural, mas, também, nos grandes centros urbanos.

Com o rádio, a música caipira, muitas vezes chamada de música de viola, ganha ainda mais espaço e admiradores por todo país. Nas letras dessas primeiras canções encontramos variados temas que abordam desde situações engraçadas e fictícias a relatos de fatos verídicos. E, embora muitas das canções relatassem o cotidiano da vida no campo, ao aguçar nossos olhares percebemos que várias das canções dessa manifestação cultural trazem à tona questões polêmicas, que causam dissenso, dividem opiniões. A violência contra a mulher é um exemplo. A música Ana Rosa (1966) composta por Carreirinho e interpretada pela dupla Tião Carreiro e Pardinho relata a atroz história de uma jovem que foi morta pelo marido no início do século XIX.

A música caipira recupera na memória uma tradição oral, pois narram causos da vida no campo, bem como as interpretações dos acontecimentos daquele cenário sob a ótica do matuto. Esse estilo musical, portanto, torna-se elemento importante para a valorização da chamada "cultura popular brasileira”. Muito embora nos dias de hoje a música de raiz tenha perdido espaço para outro gênero musical, chamado de sertanejo, com as famosas duplas de grande apelo comercial como Chitãozinho e Chororó, Zezé de Camargo e Luciano, para citar apenas algumas delas. As duplas são amparadas por artistas como Renato Teixeira, Almir Sater, entre outros, que resgatam canções brasileiras ligadas ao universo rural, o que dá aos jovens a chance de conhecer esse modo tão particular de fazer música e mover multidões pelas paixões.

\section{O pathos na música}

Escolhemos a música caipira para esta análise por vários motivos. Primeiro por estar presente desde a colonização do Brasil até a contemporaneidade adaptando-se ao contexto social, político e histórico a que está inserida. Segundo pelo fato de as melodias e as letras relatarem diversas vivências dos brasileiros, 
o que constitui importante material de pesquisa. Terceiro por representar e retratar tão bem o meio e a cultura rural de nosso país, muitas vezes esquecido pelo grande meio artístico.

A partir desse recorte, propomos como fundamentação teórica a retórica das paixões de Aristóteles para analisar a canção Ana Rosa (1966), interpretada por Tião Carreiro e Pardinho, para compreender como essa canção aborda a questão da violência contra a mulher e de que forma o enunciado desperta a compaixão e a indignação através do pathos no auditório.

Para Perelman e Olbrechts-Tyteca "toda a argumentação visa a aumentar a adesão dos espíritos e, por isso mesmo, pressupõe a existência de um contato intelectual", "para argumentar é necessário ter apreço pela adesão do interlocutor, pelo seu consentimento, pela sua participação mental”. ${ }^{2}$ A música, como todo discurso argumentativo, consiste em transpor a adesão inicial que o auditório tem relativa a uma opinião que lhe é comum para outra, de que o orador o quer convencer. Daí a importância que o orador deve possuir do seu auditório, das suas opiniões, das suas crenças, enfim, de tudo aquilo que ele tem por admitido. Estas devem ser as premissas da argumentação para o estabelecimento do contexto retórico: as teses sobre as quais há um acordo.

Estratégias persuasivas têm por objetivo levar o outro a aderir à tese apresentada no enunciado. Para isso, o orador deve utilizar-se de técnicas que levem o auditório a crer no discurso. Entre os meios de persuasão estão os que derivam da emoção despertada no ouvinte, o pathos. Para Amossy, “(...) o pathos é um componente essencial da argumentação, não como emoção expressa pelo orador, mas como tentativa de obter a adesão do auditório dirigindo-se a seus afetos", 3 as suas paixões.

Ao lado do caráter do orador (ethos) e da argumentação verdadeira ou provável (logos), as paixões constituem prova técnica, meio de persuasão pelo qual o orador faz supor que se encontra em certas disposições em relação ao auditório e, em contrapartida, suscita no auditório disposições semelhantes em relação a si. As paixões são todos aqueles sentimentos que, causando mudanças nas pessoas, fazem variar seus julgamentos. De um modo geral, o orador objetiva provocar certos efeitos no auditório e, para isso, usa determinadas estratégias linguísticas pelas quais a emoção pode ser desencadeada com o intuito de conduzi-la a um determinado juízo.

Segundo Aristóteles, as paixões humanas ou emoções "são as causas que fazem alterar os seres humanos e introduzem mudanças nos seus juízos, na

\footnotetext{
Perelman; Olbrechts-Tyteca, 1996, p. 16

Perelman; Olbrechts-Tyteca, 1996, p. 18

Amossy, 2005, p. 39
} 
medida em que elas comportam dor e prazer". ${ }^{4}$ Ao observar essa reflexão, compreendemos que elas funcionam como direcionadores sentimentais que visam introduzir um estado em um sujeito para, depois, tornar sua visão, sobre determinada questão, favorável a quem profere o discurso.

As 14 paixões apresentadas por Aristóteles (2015) na Retórica são expostas por Aristóteles como pares opostos de emoções ligados ao prazer e a dor: a ira e a calma; amizade e inimizade; temor e confiança; vergonha e desvergonha; amabilidade e indelicadeza; piedade e indignação; inveja e emulação. No entanto, apesar de não delimitar esses pares como os únicos possíveis, ele faz uma reflexão completa sobre essas emoções e como elas são despertadas nos homens.

É importante ressaltar, porém, que, na retórica, especificamente, as paixões são entendidas como "resposta a outra pessoa, e mais precisamente à representação que ela faz de nós em seu espírito. As paixões refletem, no fundo, as representações que fazemos dos outros, considerando-se o que eles são para nós, realmente ou no domínio de nossa imaginação." ${ }^{5}$ Sendo assim, nesse campo do saber, as paixões estão relacionadas a situações transitórias, provocadas pelo orador; por essa razão, não são entendidas como virtudes ou vícios permanentes. ${ }^{6}$

Como explicita Meyer ${ }^{7}$ em seu prefácio, cada uma das paixões remonta a um turbilhão, uma confusão que, apesar de desorientadora e altamente modificadora, é transitória, móvel, capaz de ser revertida e subvertida. Além disso, é um reflexo sensível do outro, ou seja, é a ponte que conecta os homens por meio do campo passional.

Ademais e, sobretudo, cada paixão despertada por um orador deflagra muito da existência do próprio sujeito que testemunha o ato discursivo. Por meio do aflorar dos sentimentos, o sujeito abre as portas do seu campo sensível, deixando que o outro conheça suas disponibilidades e, por consequência suas motivações e valores. Assim, se pensarmos no universo retórico, o orador (compositor, cantor) concebe (cria) sua música, com a finalidade de direcionar o auditório a acreditar em uma tese. Dessa maneira, a música provoca o pathos, impulsiona desejos e impele a satisfação das vontades.

\footnotetext{
Aristóteles, 2015, p. 116

Meyer, 2000, p. XLI

Cf. Fonseca, 2000, p. XV

Meyer, 2000, p. XXXIX
} 


\section{A compaixão e a indignação}

antes de adentrarmos no que Aristóteles disse sobre a compaixão, queremos apontar aqui algumas definições de compaixão já que a mesma não foi tratada somente por Aristóteles.

No dicionário Houaiss, encontramos:

MISERICÓRDIA substantivo feminino 1 sentimento de dor e solidariedade com relação a alguém que sofre uma tragédia pessoal ou que caiu em desgraça, acompanhado do desejo ou da disposição de ajudar ou salvar essa pessoa; dó, compaixão, piedade (...). 2 ato concreto de manifestação desse sentimento, como o perdão; indulgência, graça, clemência (...). (HOUAISS - versão eletrônica)

Na Bíblia, ela foi relatada na Parábola do Bom Samaritano, do novo testamento em Lucas 10:25-37, onde Jesus contou que a compaixão deveria ser aplicada a toda humanidade e aponta a visão do próximo em um sentido mais amplo, ou seja, enxergar o próximo como nós mesmos, então, faça ao seu próximo o que gostaria que fizessem a ti.

Para Arthur Schopenhauer, filósofo alemão do século XIX, a compaixão e a caridade são o contraponto do egoísmo, segundo ele o egoísmo é fruto do "eu" e do "ego" fazendo assim com que a humanidade se veja como o centro do mundo, esquecendo e se afastando do seu próximo. Para ele, é a compaixão que nos aproxima do nosso semelhante como mostra a citação a seguir:

Por isso, desejo, em oposição à forma referida do princípio moral kantiano, estabelecer a seguinte regra: com cada pessoa com que tenhamos contato, não empreendamos uma valorização objetiva da mesma conforme valor e dignidade, não consideremos portanto a maldade da sua vontade, nem a limitação do seu entendimento, e a incorreção dos seus conceitos, porque o primeiro poderia facilmente ocasionar ódio, e a última, desprezo; mas observemos somente seus sofrimentos, suas necessidades, seu medo, suas dores. Assim, sempre teremos com ela parentesco, simpatia e, em lugar do ódio ou do desprezo, aquela compaixão que unicamente forma a ágape pregada pelo evangelho. ${ }^{8}$

8 Schopenhauer, 1983, p. 188 
E Aristóteles define a compaixão "como certo pesar por um mal que se mostra destrutivo ou penoso, e atinge quem não o merece, mal que poderia sofrer a própria pessoa ou um dos seus parentes, e isso quando esse mal parece iminente", 9 ou seja, para ele a compaixão é um sentimento que nos vem da semelhança, da igualdade, nos enxergamos no lugar e o problema do outro.

A compaixão, portanto, é um sentimento que já foi citado por Jesus na bíblia, já foi estudado por grandes filósofos, como Aristóteles e ainda é muito comentada nos dias de hoje. Para Aristóteles, muitas são as causas que nos fazem sentir compaixão: os diversos tipos de morte, maus-tratos e ferimentos, doenças e falta de alimentação, carência de amigos e familiares. Diante da observação do filósofo, não precisamos fazer um esforço muito grande para pensar em cada um destes exemplos para sentir a compaixão.

Com efeito, é evidentemente necessário que quem vai sentir compaixão esteja em tal situação que creia poder sofrer algum mal, ou ele próprio ou um de seus parentes, e um mal tal como dito na definição, ou semelhante ou quase igual; por isso não sentem compaixão os que estão completamente perdidos (pois acham que nada mais podem sofrer, visto que tudo já sofreram), nem os que se julgam extremamente felizes e são, ao contrário, insolentes, porque se creem ter todos os bens, evidentemente pensam que nenhum mal possa atingi-los; de fato, esse é um dos bens. ${ }^{10}$

Como par opositor, esse mesmo auditório pode julgar sob um determinado ponto de vista ao ser conduzido à indignação diante de uma a ação que parece injusta e a pena seria merecida, mas, ao contrário do esperado, o "infrator" permanece gozando de sua liberdade e fortuna. Nesses casos, alguém, que é percebido como merecedor de castigo, está em uma clara situação de recompensa e gozo. A penalidade parece se justificar, pois o "infrator" é apresentado como beneficiado e se deleita por uma "felicidade imerecida". O auditório é levado a se indignar, pois "não é justo que aqueles que não são nossos iguais sejam julgados dignos de bens iguais os nossos"11 e, uma vez que as ações deles são repreensíveis, não deveriam gozar do conforto, da riqueza e da felicidade.

\footnotetext{
9 Aristóteles, 2000, p. 53

10 Ibid., p. 53

11 Aristóteles, 2005, II, 1387b-1388a
} 
A indignação é uma modalidade natural de ódio ou de aversão que se sente por aqueles que praticam algum mal, de qualquer natureza que seja; e muitas vezes está misturado com a inveja ou com a compaixão; porém seu objeto é completamente diferente, já que ficamos indignados somente contra os que fazem o bem ou o mal às pessoas que não o merecem, mas temos inveja dos que recebem esse bem, e sentimos compaixão pelos que recebem esse mal. É verdade que, de alguma forma, possuir um bem de que não se é merecedor significa praticar o mal; o que talvez tenha sido a causa pela qual Aristóteles e seus seguidores, presumindo que a inveja é sempre um vício, deram o nome de indignação àquela que não é viciosa. ${ }^{12}$

\section{As paixões na canção Ana Rosa}

Ana Rosa casou-se aos 15 anos com Francisco Carvalho Bastos, conhecido como Chicuta, influente carreiro de idade entre 40 e 45 anos. Chicuta era tempestivo, ciumento e machista, maltratava e batia em sua mulher frequentemente. Ana Rosa, por sua vez, não mais aguentando os maus-tratos sofridos pelo marido, decide aproveitar a ausência dele para uma de suas viagens e foge a cavalo com a ajuda de um escravo. Ela parte para Botucatu e recebe abrigo da tia que era costureira em um cabaré, porém, ao voltar de viagem, Chicuta descobre tudo e parte, furioso, em busca de sua esposa. Ele tenta tirá-la à força do local, mas foi impedido pela tia da moça e por D. Fortunata Jesuína de Melo, dona do bordel. Inconformado e cego de ódio, ele arma uma emboscada contratando dois capangas. Um deles era José Antonio da Silva Costa, conhecido por Costinha e foi ele quem conseguiu conquistar a confiança da moça para atraí-la até a emboscada.

O plano de Costinha foi executado com sucesso e a moça foi assassinada na madrugada do dia 21 de junho de 1885 . No dia seguinte pela manhã, um fazendeiro da região de Botucatu encontrou um corpo mutilado. $\mathrm{O}$ corpo foi reconhecido graças a relatos de uma escrava que testemunhou escondida a barbárie e conseguiram chegar até os assassinos da moça. A tragédia ecoou e entristeceu toda a cidade de Botucatu e, sua história permanece viva. Muitos são os relatos e mistérios envolvidos na história, mesmo hoje, 135 anos após a morte. Há simpatizantes de sua história que relatam milagres devotados à jovem 
moça, em seu túmulo tem mais de 200 placas em agradecimento de pessoas que afirmam ter alcançado graças por intercedência dela.

Sua história foi imortalizada de várias formas: em um filme de produção independente de Davi Franque, postado em 27 de março de 2018. Em meados de 2000, De Teatro Notívagos Burlescos adaptou a história para uma peça de teatro e outro grupo da região, os Anônimos da Arte, também adaptaram a tragédia para os palcos. E, nos anos 1990, a história também chamou a atenção do memorialista Moacir Bernardo e como resultado decidiu pesquisar documentos de época. Foi então que em 1998 lançou o livro "Ana Rosa - Sua Vida, Sua História”.

Mas, antes de ela ter ganhado as versões em teatro e livro, a história já tinha sido relatada pelo compositor Carreirinho. Ele compôs uma música em que a letra conta toda a história e, em 1966 (no disco "Linha de frente") a dupla sertaneja Tião Carreiro e Pardinho grava a canção relatando toda a trágica história de uma jovem de apenas 20 de idade do século XIX.

\section{Ana Rosa}

Tião Carreiro e Pardinho - Composição: Carreirinho

Ana Rosa casou com Chicuta, um caipira bastante atrasado

Levava a vida de carreiro fazendo transporte, era o seu ordenado

Tinha um ciúme doentio pela moça que dava pena do coitado

Batia na pobre mulher com a vara de ferrão de bater no gado, ai

Resorveu abandonar o marido porque a vida já não resistia

Quando chegou em Botucatu, aquela cidade toda dormia

Só encontrou uma porta aberta, mas ali não entrava família

Resolveu contar sua história e se abrigar até no outro dia

O Chicuta quando chegou em casa, Ana Rosa, não encontrou

Ele arreou sua besta e como uma fera a galope, tocou

$\mathrm{Na}$ chegada de Botucatu, prum caboclo ele perguntou

Seu moço, essa mulher lá na Fortunata, vi quando ela entrou, ai

Num barzinho ali da saída, sem destino, resolveu chegar

Encontrou com um tar de Menegirdo e com o Costinha pegou conversar Vocês querem pegar uma empreitada? Só se for pra não trabalhar

Pra matar a minha mulher, minha proposta vai lhe agradar, ai

O Costinha montou a cavalo e tocou lá pra Fortunata

Conversando com Ana Rosa, disse que era um tropeiro da Zona da Mata Meu patrão lhe mandou uma proposta, diz que leva e nunca lhe maltrata Seu marido anda à sua procura, jurou que encontrando, ele te mata Ana Rosa montou na garupa e o cavalo saiu galopeando 
Quando chegou no lava-pé aonde os bandido já estava esperando Quando ela avistou seu marido, para todo santo foi chamando Vou perder minha vida inocente, partirei com Deus deste mundo tirano, ai Dirrubaro ela da garupa já fazendo cruel judiação

Foi cortando ela aos pedaços, uma preta assistindo a cruel judiação Foi correr dar parte à autoridade, já fizeram imediata prisão Hoje lá construíram uma Igreja, tem feito milagre pra muitos cristão.

O discurso proferido acima revela a barbárie que aconteceu com Ana Rosa, uma jovem de 20 anos de idade do século XIX, época que a mulher era completamente submissa aos homens em todos os aspectos. Hoje encontramos livros, documentários e em outras letras de músicas histórias de "outras Ana Rosas". As mulheres ganharam o direito de liberdade de escolha, trabalho, bem como do seu próprio parceiro há pouco tempo e sabemos que a luta ainda continua e esse espaço, bem como o respeito, ainda não foi conquistado.

Um exemplo de que essa batalha ainda está longe de acabar são os dados notificados pela Lei 11.340, Lei Maria da Penha. Os noticiários apontam que somente 1 em cada 3 mulheres denunciam seu agressor e, atualmente, por conta da COVID-19, que nos levou ao isolamento social, o caso de agressões à mulher aumentou e $54 \%$ na Bahia, segundo o site CORREIO24horas. ${ }^{13}$

A letra da música acima descrita deixa claro a todo momento essa violência direcionada à Ana Rosa e as atitudes machistas de Chicuta. A finalidade do orador é o movere, instaurando no auditório através do pathos, a Indignação por Chicuta e a Compaixão por Ana Rosa. Inicialmente a letra já nos traz as características de um homem extremamente violento que era o Chicuta: um caipira bastante atrasado, tinha um ciúme doentio pela moça, batia na pobre mulher com a vara de ferrão de bater no gado. O orador aponta, logo de início, dois fortes motivos dele ter sido qualificado por "um caipira bastante atrasado": o ciúme doentio e o fato dele bater na pobre mulher com a vara de ferrão de bater no gado. Nota-se que o orador expõe as características violentas de Chicuta em vários trechos do discurso: o Ele arreou sua besta e como uma fera a galope, tocou, Pra matar a minha mulher, ele te mata, e, ao final do da letra, o orador fecha com as ações violentas que ele exerce sobre sua mulher: Dirrubaro ela da garupa já fazendo cruel judiação, foi cortando ela aos pedaços.

13 Disponível em: https://www.correio24horas.com.br/noticia/nid/denuncias-de-violencia-contra-mulhercrescem-54-durante-a-pandemia/ 
As duas paixões se misturam no meio do discurso porque ele já aponta o temperamento cruel de Chicuta e esse temperamento é mostrado em vários trechos como mostramos no parágrafo anterior, e, em seguida ele aponta a fragilidade de Ana Rosa, a pobre mulher, e quando e o porquê ela resolveu abandonar o marido, no momento em que decide procurar abrigo em uma "casa onde não entrava família", mas resolveu ficar ali mesmo assim para pedir abrigo e proteção. O orador ainda aproveita da inocência de Ana Rosa, fazendo com que ela acredite que Costinha era um tropeiro da Zona da Mata e que ele a levaria para um lugar seguro a mando de seu superior Meu patrão lhe mandou uma proposta, diz que leva e nunca lhe maltrata e ainda instaura o medo nela ao dizer que Seu marido anda à sua procura, jurou que encontrando, ele te mata.

$\mathrm{O}$ discurso reforça a todo instante a compaixão provocada pelo orador através do pathos. Ana Rosa é acometida e desrespeitada a todo o momento. $\mathrm{O}$ discurso não aponta, porém, todos os detalhes e fatos que aconteceram com ela. Não relata, por exemplo, que os três criminosos (dois capangas mais o Costinha, autor e marido da vítima) não foram imediatamente autuados após o crime e nem condenados como o esperado quando julgados, como vemos no trecho retirado do site $\mathrm{BBC}$ News Brasil ${ }^{14}$ sobre o julgamento dos três envolvidos no crime:

Os assassinos foram a julgamento, mas Chicuta foi absolvido, alegando ter cometido o crime em defesa de sua honra. Costinha, por ser de uma família rica da região, também foi absolvido. O único condenado foi o capanga Hermenegildo Vieira do Prado, conhecido como Minigirdo, filho de escravos.

Essas paixões opostas descritas por Aristóteles retratam bem o relato da canção. Sentimos compaixão pelo infortúnio da mulher que perdeu sua vida pelas mãos daquele que, em tese, deveria zelar pelo seu bem estar. E Indignação por Chicuta não ter recebido a pena que merecia. Muito embora na letra o autor do crime tenha sido preso ele não teve o mesmo final trágico da mulher.

Dessa forma o auditório é levado a "sentir aflição e compaixão pelos que são infelizes sem o merecer, e indignação pelos que imerecidamente são felizes". ${ }^{15}$ Este sentimento é instaurado desde o início do discurso e transcorre até o final. Chicuta sempre executou a violência contra Ana Rosa e nunca foi detido, sempre foi livre, trabalhava e ganhava seu dinheiro. Essa prova extrínseca está exposta no trecho inicial quando fala que ele Levava a vida de carreiro fazendo trans-

14 Disponível em: https://www.bbc.com/portuguese/brasil-46070076

15 Aristóteles, 2000, p. 59 
porte, era o seu ordenado. O trecho final descreve o êxito que ele teve, conseguiu convencê-la para a emboscada da morte através de Costinha, seu capanga, e a esquarteja, sem piedade.

Além disso, percebemos que o discurso reforça estereótipos de gêneros, como a sujeição do feminino ao masculino. Ana Rosa, ao fugir de Chicuta, transgride os códigos do casamento e, por isso, é passível de uma punição. A fuga da mulher constitui para Chicuta uma luta, um enfrentamento de sua autoridade. O desfecho da história põe os personagens da história em segundo plano em detrimento das ações. Além disso, o fim trágico mostra uma ação reguladora de uma sociedade com raízes machistas. As mulheres, que não se submete às obrigações matrimoniais, tendem a ter um fim trágico.

Devemos pensar aqui que o auditório dessas canções é universal e a morte de Ana Rosa pode, ou não, provocar as mesmas paixões no auditório. Ou seja, as ações podem afetar o ouvinte, mas não necessariamente vem acompanhadas de uma atividade reflexiva. "Os fatos não se apresentam sob o mesmo prisma a quem ama e a quem odeia, nem são iguais para o homem que está indignado ou para o calmo, mas, ou são completamente diferentes ou diferem segundo critérios de grandeza". ${ }^{16}$

\section{Considerações Finais}

O orador, ao abordar temas como a violência contra a mulher, buscar persuadir o auditório a pensar em um tema tão polêmico e, ao mesmo tempo, tão presente na vida das pessoas. No entanto, segundo Meyer, o "orador deve levar em consideração as paixões do auditório, pois, se elas exprimem o aspecto subjetivo de um problema, respondem a ele, também, em função dos valores da subjetividade implicada". ${ }^{17}$

O som é constitutivo dos sentidos e, quando articulado em formas artísticas, se revela e produz sentido nas canções. Cremos, como muitas pessoas, que a música pode ser considerada a arte que mais se destaca dentre todas as demais, pois, além de estar presente em qualquer sociedade desde as civilizações mais antigas até hoje, exerce também grande influência no comportamento dos homens.

Assim, no universo retórico, o orador (compositor, cantor), concebe (cria) sua música, com a finalidade de direcionar o auditório a acreditar em uma tese. Dessa maneira, a música provoca o pathos, impulsiona desejos e impele a satisfação das vontades.

16 Id., Retórica, 2005, II, 1377b-1378a

17 Meyer, 2007, p. 39 
Nas canções analisadas, com a nítida finalidade de mover seu auditório pelas paixões através do pathos, o orador cria, a todo o momento, um ambiente propício no seu discurso enfatizando duas paixões específicas: a compaixão e a indignação. Não é por acaso que Aristóteles classifica as paixões em pares opostos. Há uma estreita ligação entre elas. No caso da canção percebemos claramente as duas paixões nos papeis dos protagonistas.

A música é uma expressiva forma de demonstração da arte nacional e que os compositores e compositoras concebem, no ato criativo, traços caracteristicamente brasileiros. Nesse sentido, o ethos e o pathos se traduzem pelo esforço consciente de muitos e muitos compositores que, à sua maneira, traduzem fortes aspectos psicológicos e sociais do brasileiro comum.

\section{Referências}

AMOSSY, R. (org.). Imagens de si no discurso: a construção do ethos. São Paulo: Contexto, 2005.

ARISTÓTELES. Retórica das paixões. São Paulo: Martins Fontes, 2015. (edição bilíngue: grego-português).

BÍBLIA. Disponível em: https://www.bibliaonline.com.br/acf/lc/10/25-37

DESCARTES. R. As Paixões da Alma. In: Descartes (Coleção Os Pensadores). São Paulo, SP: Editora Nova Cultural, 1999. pp. 101-245.

HOUAISS. Dicionário Houaiss da Língua Portuguesa. Versão eletrônica. 2001.

MEYER, M. As paixões nos diálogos platônicos. In: ARISTÓTELES. Retórica das paixões. Tradução de Isis Borges da Fonseca. São Paulo: Martins Fontes, 2000.

MEYER, M. A retórica. Revisão técnica Lineide Salvador Mosca; tradução Marly N. Peres. São Paulo: Ática, 2007.

SCHOPENHAUER. Aforismos para a Sabedoria na Vida. São Paulo: Melhoramentos, 1983. PERELMAN, C.; OLBRECHTS-TYTECA, L. Tratado da Argumentação: a nova retórica. Prefácio de Fábio Ulhôa Coelho e tradução de Maria Ermantina Galvão G. Pereira. São Paulo: Martins Fontes, 1996. 